Original Research Paper

\title{
Effect of Niobium Oxide Incorporation on Optical Properties of Sodium Bismuth Borate Glasses
}

\author{
${ }^{1}$ Hossam M. Gomaa, ${ }^{2}$ Saeid M. Elkatlawy and ${ }^{3}$ Ahmed H. El-Dosokey

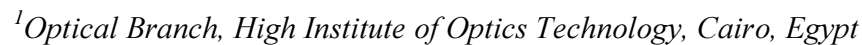 \\ ${ }^{2}$ Department of Physics, Faculty of Science, Damanhour University, Damanhour, Egypt \\ ${ }^{3}$ Department of Physics, Faculty of Science, El-Fayoum University, El-Fayoum, Egypt
}

Article history

Received: 06-04-2019

Revised: 22-06-2019

Accepted: 05-07-2019

Corresponding Author: Dr. Saeid M. Elkatlawy Department of Physics, Faculty of Science, Damanhour University, Damanhour, Egypt Email: saeid.elkatlawy@gmail.com

\begin{abstract}
Glasses with the chemical compositions $60 \% \mathrm{~B}_{2} \mathrm{O}_{3}-20 \%$ $\mathrm{Na}_{2} \mathrm{O}-(20-x) \% \mathrm{Bi}_{2} \mathrm{O}_{3}-x \% \mathrm{Nb}_{2} \mathrm{O}_{5}$ (where, $x=0,5,10$ and 15 mol. \%), were prepared by fast quenching of their melts. Characteristics of the obtained solids were checked by XRD, FTIR and optical absorption spectroscopy. XRD data confirmed the amorphous nature of the glass samples. FTIR results revealed no changes in the ratio of the structural units $\mathrm{BO}_{3}: \mathrm{BO}_{4}$ when replacing $\mathrm{Bi}_{2} \mathrm{O}_{3}$ by $\mathrm{Nb}_{2} \mathrm{O}_{5}$. Moreover, both $\mathrm{Bi}^{3+}$ and $\mathrm{Nb}^{5+}$ cations occupied octahedral coordination states and both acted as glass network modifiers. Optical studies affirmed that the lowest value of both direct and indirect optical band gaps was obtained in samples with equal concentration of $\mathrm{Nb}_{2} \mathrm{O}_{5}$ and $\mathrm{Bi}_{2} \mathrm{O}_{3}$. All optical absorption bands were elucidated in terms of the terminal oxygen atoms around $\mathrm{Nb}^{5+}$ and $/ \mathrm{or} \mathrm{Bi}^{3+}$ cations. The optical nonlinearity of the glass samples was assessed in terms of absorption coefficient and the value of the optical band gap.
\end{abstract}

Keywords: Sodium Bismuth Niobium Borate Glass, Absorption Coefficient, Direct and Indirect Optical Band Gaps, Optical Nonlinearity

\section{Introduction}

Nonlinear optical behavior of amorphous materials has been extensively studied by several researchers because of its promising usage in photonic devices applications (Boyd, 2003; Sutherland, 2003). In this regard, bismuth borate glasses have caught great attention due to their facile and low cost synthesis, enhanced mechanical and chemical stability, in addition to the large range of nonlinear refractive index and nonlinear absorption coefficient (Farouk et al., 2013; Shanmugavelu et al., 2013). Furthermore, borate glasses doped with heavy metal oxides show interesting nonlinear optical properties and have different application in microscopic lens designing (Ehrt, 2000). Bismuth oxide doesn't play the role of a glass former; it is rather a good modifier that enhances optical, thermal and structural characteristics of the glass (Oo et al., 2012). It also increases the ratio of the non-bridging oxygen (NBO) and therefore enhances the glass absorbability (Chen et al., 2008; Pal Singh et al., 2012). The decrease of the number of NBO is associated to an increase in the optical band gap (Novatski et al., 2008). Bismuth is likely occupying octahedral coordination in the $\mathrm{Bi}_{2} \mathrm{O}_{3}$ oxide inside the glass network, which contributes in the existence of NBO (Rajendran et al., 2003). The presence of transition metal niobium oxide $\mathrm{Nb}_{2} \mathrm{O}_{5}$ in glasses elevates chemical stability and improves the mechanical properties (Sene et al., 2004). It was reported that introducing niobium oxide into the glass matrix increases the activation energy and the glass transition temperature $T_{g}$ (Sene et al., 2004). Optical properties such as optical band gap and optical basicity were strongly improved when $\mathrm{Nb}_{2} \mathrm{O}_{5}$ was introduced into the glass system containing $\mathrm{Bi}_{2} \mathrm{O}_{3}$ (Sanghi et al., 2010; Swapna et al., 2017). The largest value of the non-linear refractive index was reported to glasses containing empty $\mathrm{d}$ shell transition metal ions such as $\mathrm{Nb}^{5+}$ (Cardinal et al., 1997). Furthermore, by incorporating $\mathrm{Nb}_{2} \mathrm{O}_{5}$ in the glass network, the $\mathrm{Nb}^{5+}$ cation acts as a network former and improves the third order nonlinear optical susceptibility (Suhara et al., 2012). The usual coordination of $\mathrm{Nb}^{5+}$ cation in oxide glasses is octahedral. Therefore, niobium atoms are located in octahedral sites. The non-linear refractive index was reported to increase proportionally to the concentration of $\mathrm{Nb}^{5+}$ cation in the glass system (Couzi et al., 1996). It was assumed that the polarization of the niobium oxygen bond is the main contribution to the optical non-linearity (Cardinal et al., 1997). Recalling that nonlinear optical behavior of glasses is improved by adding lone-pair holder such as $\mathrm{Bi}^{3+}$ or cation of empty $\mathrm{d}$ shell such as $\mathrm{Nb}^{5+}$ (Chen et al., 2008). 
Table 1: Calculation of the field strength for each oxide in the mixture

\begin{tabular}{llllr}
\hline & $\mathrm{B}_{2} \mathrm{O}_{2}$ mol. \% & $\mathrm{Na}_{2} \mathrm{O}$ mol. \% & $\mathrm{Bi}_{2} \mathrm{O}_{3}$ mol. \% & $\mathrm{Nb}_{2} \mathrm{O}_{5} \mathrm{mol.} \mathrm{\%}$ \\
\hline Molecular Weight & 69.59 & 61.98 & 465.99 & 265.82 \\
Field Strength & 1.5 & 0.19 & 0.65 & 0.94 \\
Role of oxide & Former & Modifier & Intermediate & \\
Nb Composition & & & 20 & 0.00 \\
$0 \%$ & & & 15 & 5.00 \\
$\mathbf{5 \%}$ & \multirow{2}{*}{} & & 10 & 10.00 \\
$10 \%$ & & & 5 & 15.00 \\
$15 \%$ & & & & \\
\hline
\end{tabular}

The aim of the present work is to study the optical characteristics of sodium bismuth niobium borate glasses in relation to the replacement of bismuth oxide by niobium oxide.

\section{Experimental Work}

High purity starting materials, not less than $99 \%$, were used to prepare the suggested compositions, as indicated in Table (1). To find out the role of each oxide in the mixture, the field strength was calculated for each oxide using relation (1):

$$
F_{C_{a} O_{b}}=\frac{z_{c}}{\left(r_{c}+r_{o}\right)^{2}}
$$

where, $F$ is the field strength of oxide $C_{a} O_{b}, Z_{c}$ and $r_{c}$ are the oxidation state and covalent radius of the cation $\mathrm{C}$ and $r_{o}$ is the covalent radius of oxygen ion (Pye, 2005; Rao, 2002; Shelby and Lopes, 2007).

Oxide precursors were weighted by 4-digits balance, mixed well together in porcelain crucibles and then melted for $2 \mathrm{~h}$ at $900 \pm 50^{\circ} \mathrm{C}$, in an electric furnace. Melts were then solidified by rapid quenching in air onto pre-cooled copper plates. X-ray powder diffractometer (Rigaku Miniflex, Japan), with $\mathrm{Cu} \mathrm{K} \alpha$ radiation (1.54 $\AA$ ), was used for XRD analysis in order to check the formation of glasses. In order to obtain information about structural units for the studied samples, infrared spectra were recorded using Fourier Transform Infrared (FTIR) Jasco 5300 spectrometer. Parts of the solidified glass samples were powdered and diluted in dry $\mathrm{KBr}$, pressed in pellets form and measured at room temperature over the range from 4000 to $400 \mathrm{~cm}^{-1}$. Optical absorption spectra were recorded in the range from 200 to $2500 \mathrm{~nm}$ using Genway 6405 UV-VIS spectrophotometer.

\section{Results and Discussion}

\section{XRD Data}

Figure 1 shows the x-ray diffractograms of all samples, with no observed sharp peaks. Only one broad hump was observed around $2 \theta=47^{\circ}$. Such observation refers to the amorphous nature of the prepared solids, with short ordered structure. Each sample, in the studied glasses, contains 60 mol. $\%$ of $\mathrm{B}_{2} \mathrm{O}_{3}$ which is considered as the glass former oxide with two remarkable structural units $\mathrm{BO}_{3}$ and $\mathrm{BO}_{4}$. In addition to 20 mol. $\%$ of both $\left(\mathrm{Bi}_{2} \mathrm{O}_{3}+\right.$ $\mathrm{Nb}_{2} \mathrm{O}_{5}$ ), that are considered as intermediate oxides with the ability to act as glass network formers and/or glass network modifiers. From $\mathrm{x}$-ray diffraction tables, the hump observed at $2 \theta=47^{\circ}$ is a characteristic of the noncrystalline $\mathrm{Bi}_{2} \mathrm{O}_{5}$ (Junjiang et al., 2002). This result affirms that some/all $\mathrm{Bi}_{2} \mathrm{O}_{3}$ did not participate in the glass matrix as a glass former, but rather as a network modifier.

\section{FTIR Spectra}

Figure 2 shows the FTIR spectra for all glass samples and it is clear that the spectrum of each sample can be divided into two spectral zones. The first zone shows the vibrational bands of $\mathrm{OH}-$ groups, in the wavenumber from 4000 to $1800 \mathrm{~cm}^{-1}$ (El-Maaref et al., 2017; Yiannopoulos et al., 2001). While the second zone, limited in the range from 1800 to $400 \mathrm{~cm}^{-1}$, contains four broad vibrational bands centered at 1370, 980, 703 and $456 \mathrm{~cm}^{-1}$. Referring to the related previous publications, all observed bands in the second zone were attributed to their structural units or bonds. Whereas, the bands centered at 1370 and $980 \mathrm{~cm}^{-1}$ are due to asymmetric stretching vibrations of $\mathrm{B}-\mathrm{O}$ in $\mathrm{BO}_{3}$ units (El-Maaref et al., 2017; Yiannopoulos et al., 2001) and stretching vibrations of $\mathrm{B}-\mathrm{O}$ in $\mathrm{BO}_{4}$ units, respectively (Rao et al., 2016). Band located around $703 \mathrm{~cm}^{-1}$ may be attributed to the bending vibrations of oxygen atoms in $\mathrm{B}-\mathrm{O}-\mathrm{B}$, in $\mathrm{BO}_{3}$ units and/or symmetric stretching of the edge-sharing oxygen atoms in $\mathrm{Nb}-\mathrm{O}$ bond of in $\mathrm{NbO}_{6}$ groups (Balachander et al., 2013; Fragoso et al., 2005). Such band may indicate that $\mathrm{Nb}^{5+}$ have octahedral coordination numbers, which indicates that these cations did not share in the glass network but occupy the interstitial vacancies. While $456 \mathrm{~cm}^{-1}$ band is due to the $\mathrm{Bi}-\mathrm{O}$ valence band vibrations of $\mathrm{BiO}_{6}$ structural units and/or the angle modification of the boron oxygen bond linkage (El-Maaref et al., 2017; Sutherland, 2003).

Moreover, it is clear that bands of $\mathrm{BO}_{4}$ became higher and broader than those of $\mathrm{BO}_{3}$ when $\mathrm{B}_{2} \mathrm{O}_{3}$ is replaced by $\mathrm{Nb}_{2} \mathrm{O}_{5}$. In other words, the relative number of compositional group $\mathrm{BO}_{3}$ decreased while that of $\mathrm{BO}_{4}$ increased when $\mathrm{B}_{2} \mathrm{O}_{3}$ replaced by $\mathrm{Nb}_{2} \mathrm{O}_{5}$, as seen in Fig. 3 . 


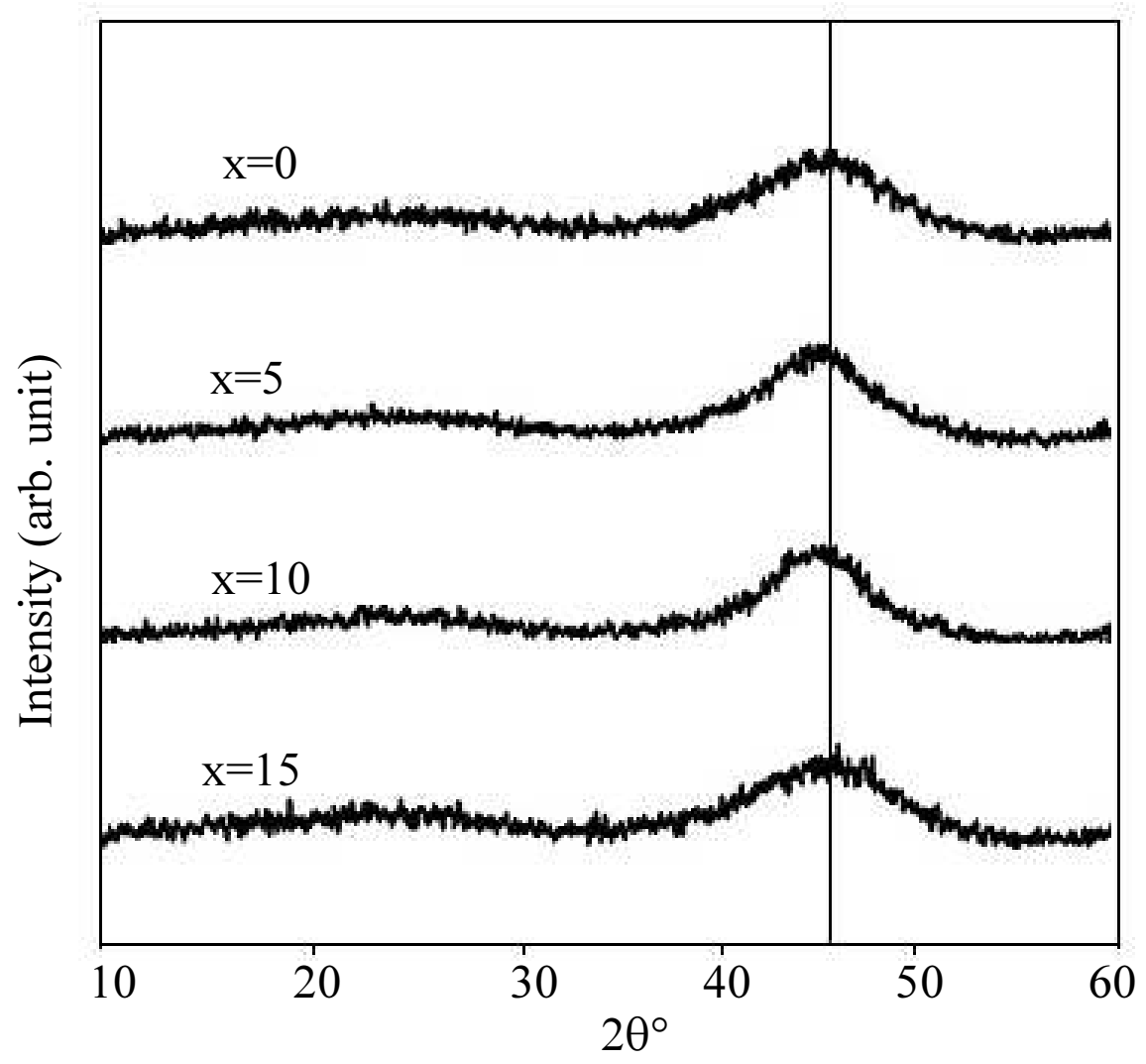

Fig. 1: X-ray diffraction pattern for all samples

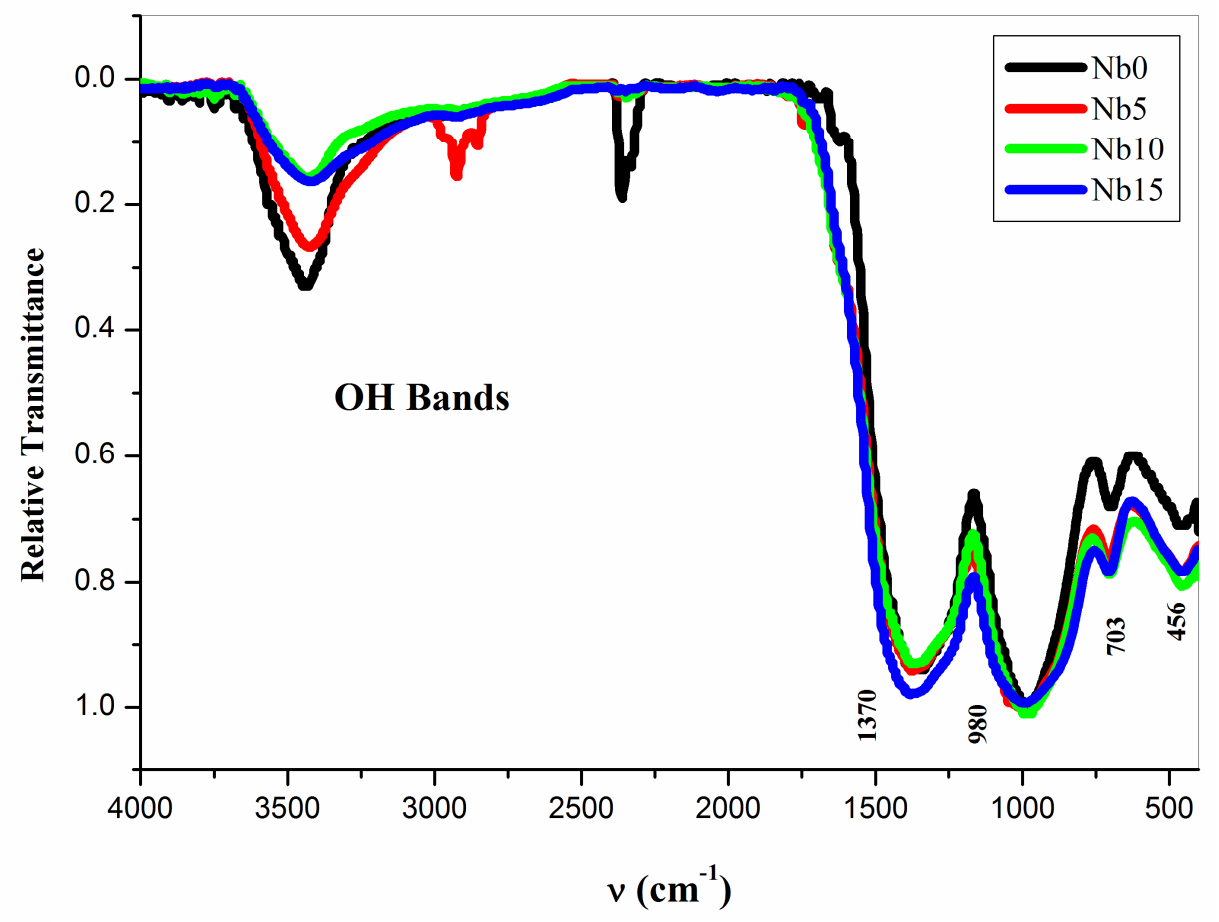

Fig. 2: FTIR spectra for all samples, with functional groups assigned 


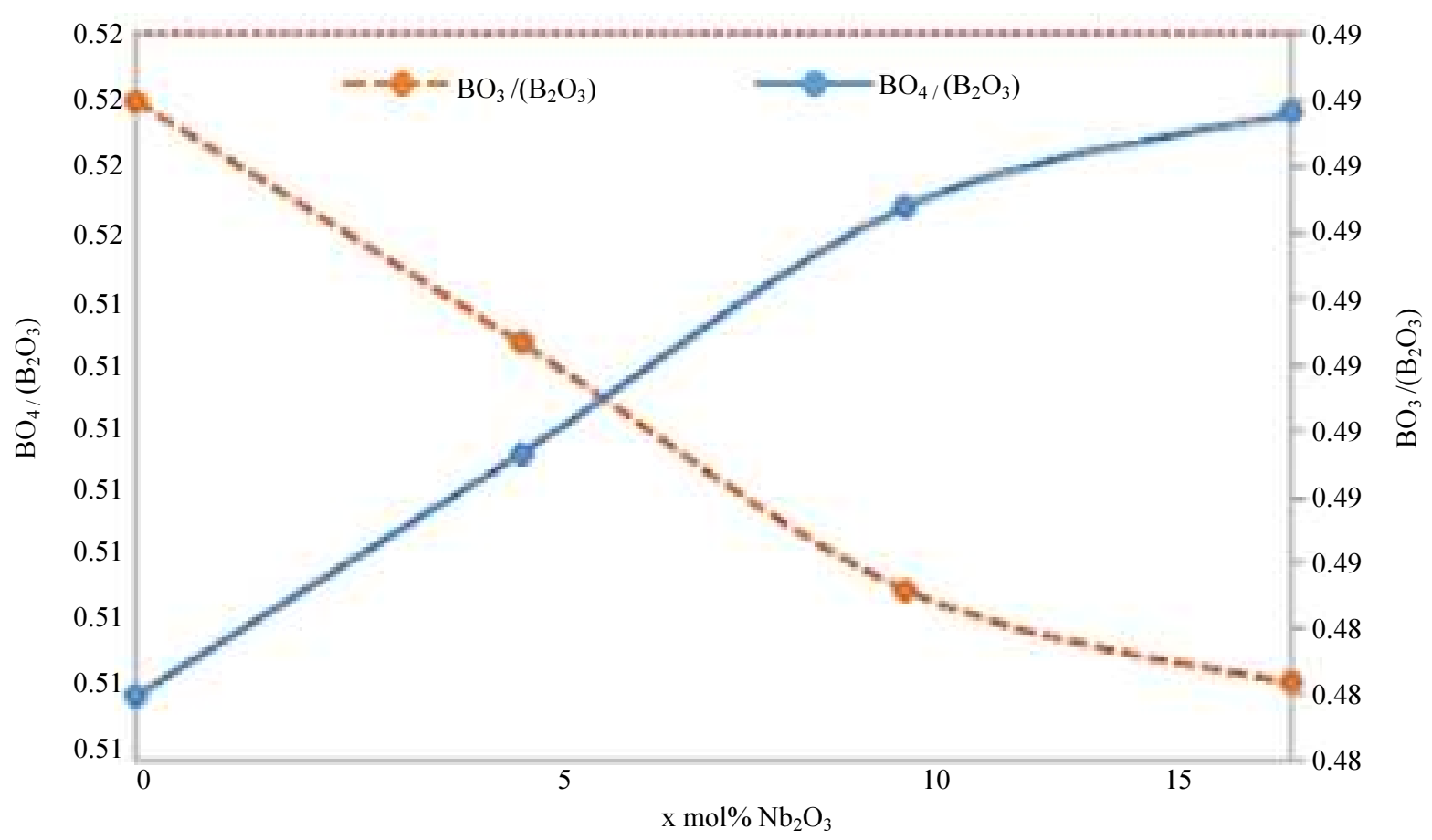

Fig. 3: Relative number of compositional groups $\mathrm{BO}_{4}$ and $\mathrm{BO}_{3}$ as a function of the concentration of $\mathrm{Nb}_{2} \mathrm{O}_{5}$ in mol. \%

This behavior is due to the richness of $\mathrm{Nb}_{2} \mathrm{O}_{5}$ in oxygen than $\mathrm{B}_{2} \mathrm{O}_{3}$. Therefore, it can be concluded that the increase in $\mathrm{Nb}_{2} \mathrm{O}_{5}$ concentration induces the glass matrix to be more homogenous and open structure, in agreement with the published work (Yiannopoulos et al., 2001).

\section{Optical Absorption Spectra}

Figure 4 shows the relative optical absorption spectra of the studied glasses. All samples have the same cutoff wavelength $\left(\lambda_{\text {cutoff }}=443 \mathrm{~nm}\right)$, with no observed absorption peaks in UV region (200-400 nm). By careful inspection of Fig. 4, two well defined absorption bands can be observed, the first one is a broad band extended from $700 \mathrm{~nm}$ to $1000 \mathrm{~nm}$, its center shifted from 810 to $825 \mathrm{~nm}$ (red shift) when $\mathrm{Bi}_{2} \mathrm{O}_{3}$ was exchanged by $\mathrm{Nb}_{2} \mathrm{O}_{5}$. The second band appeared in region from 1000 to 2500 $\mathrm{nm}$ and is peaked at $1745 \mathrm{~nm}$. The red shift noticed from $810 \mathrm{~nm}$ to $825 \mathrm{~nm}$ may be attributed to the change in the glass optical basicity because of the variations of $\mathrm{OH}-$ groups, in addition to presence of niobium oxide and the consequence change in the energy levels (Duffy and Ingram, 1971; Stehle et al., 1998). Also, it is clear that the increase of $\mathrm{Nb}_{2} \mathrm{O}_{5}$ content increased the intensity and broadness of the absorption peaks. Such behavior may indicate that, the content of $\mathrm{OH}-$ in the glass network increased by increasing $\mathrm{Nb}_{2} \mathrm{O}_{5}$, the thing which mean low density, high molar volume and good amorphous nature for the studied glass system. By surveying previous related publications, it can be stated that the observed optical absorption may be attributed to deformation in the glass networks due to the interstitial impurities in addition to the octahedral forms of both $\mathrm{Bi}^{3+}$ and $\mathrm{Nb}^{5+}$ cations (Stehle et al., 1998). But, according to ligand field theory the positive transition metal ion is always attached to negatively charged ligands (Figgis, 1987), so the observed absorption may be attributed to the presence of the non-bridging oxygen (NBO) ions that surround each $\mathrm{Nb}^{5+}$ cation. It should take into consideration that the increase in NBO may cause the third-order susceptibility to arise and hence improves the nonlinear behavior of the glass (Almeida et al., 2011). Accordingly the broadness of the absorption band may be explained as consequence of the relative increase in the number of NBO in the ligand, by replacement the poor-inoxygen $\mathrm{Bi}_{2} \mathrm{O}_{3}$ by the rich-in-oxygen $\mathrm{Nb}_{2} \mathrm{O}_{5}$. The effect of niobium oxide arises from electronic d-d transitions and the coupling between the d-electrons of $\mathrm{Nb}^{5+}$ and the vibrations of the negatively charged $\mathrm{O}^{2-}$ in the ligands.

On the other hand, it is well known that the analysis of absorption edges gives precise information about the value of optical band gap (Hodgson, 2012; Meyer et al., 1998). It is also known that the value of absorption coefficient $\alpha$ increase as a consequence of light absorption. This change in $\alpha$ is known as the fundamental absorption edge and is related to the absorbed energy by the relations given (Davis and Mott, 1970; Tauc and Menth, 1972) for direct allowed transitions by $\alpha h v \propto\left(h v-E_{o p t}\right)^{\frac{1}{2}}$ and for indirect allowed transitions by $\alpha h v \propto\left(h v-E_{o p t}\right)^{2}$, where $h v$ is the incident photon energy and $E_{\text {opt }}$ is the optical energy gap. 
Table 2: Values of cutoff frequency, direct band gap, and indirect band gap for the four samples

\begin{tabular}{llll}
\hline$x \% \mathrm{Nb}_{2} \mathrm{O}_{5}$ & $\lambda_{\text {cutoff }}(\mathrm{nm})$ & $\left(E_{\text {Opt }}\right)^{d}(\mathrm{eV})$ & $\left(E_{\text {Opt }}\right)^{i}(\mathrm{eV})$ \\
\hline 0 & & 2.43 & 1.63 \\
5 & 443 & 2.06 & 1.24 \\
10 & & 1.95 & 0.58 \\
15 & 2.20 & 1.04 \\
\hline
\end{tabular}

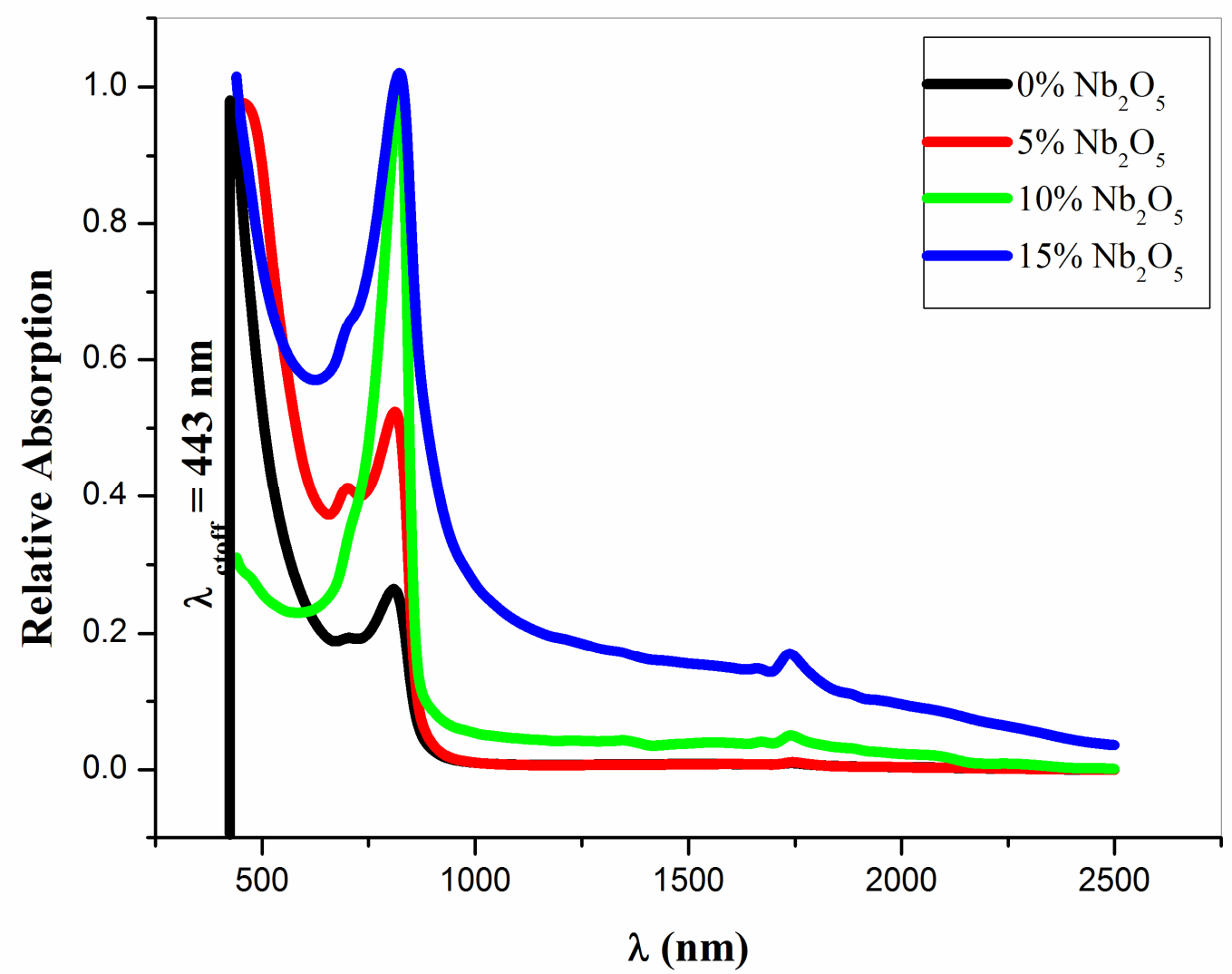

Fig. 4: Relative absorption spectra for all samples in between 200 and $2500 \mathrm{~nm}$
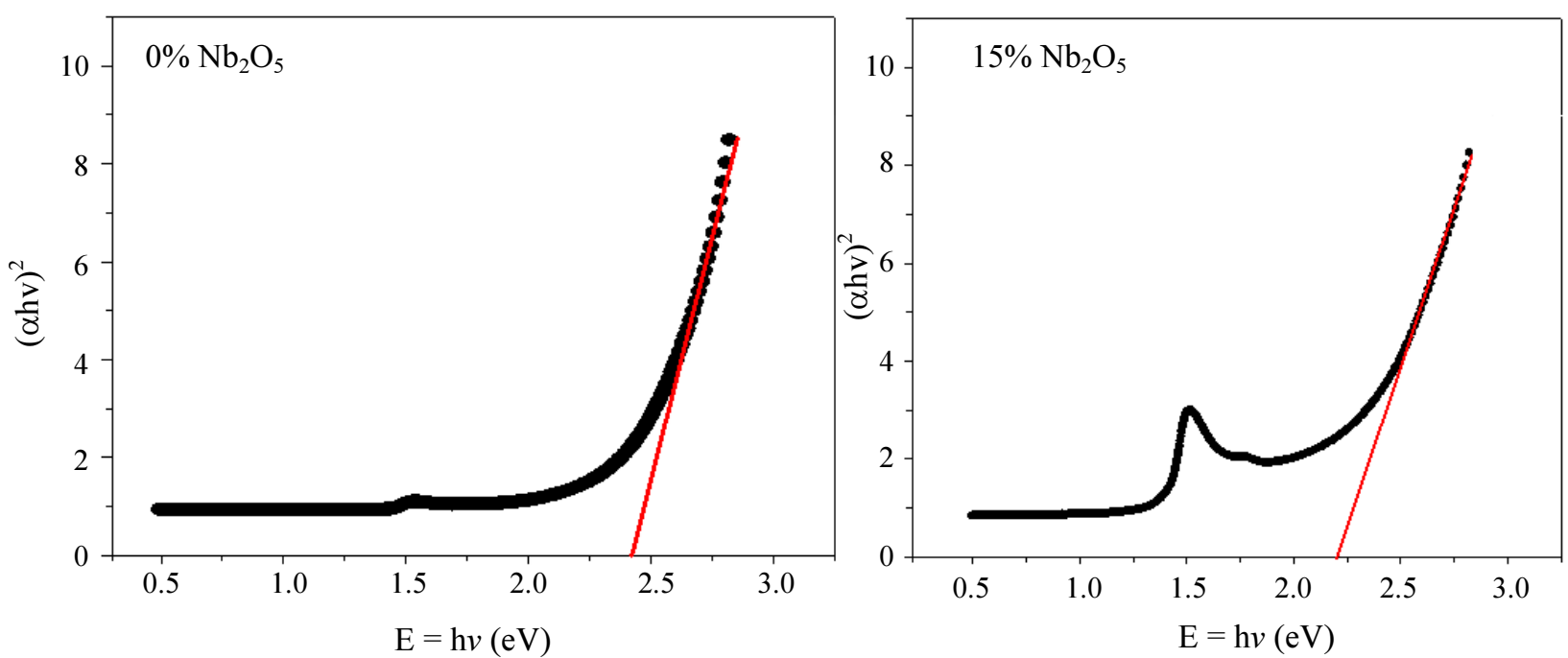

Fig. 5: $(a h v)^{2} v s . h v$ for direct allowed transition in the niobium free $(\mathrm{x}=0)$ and bismuth free $(\mathrm{x}=15)$ samples 

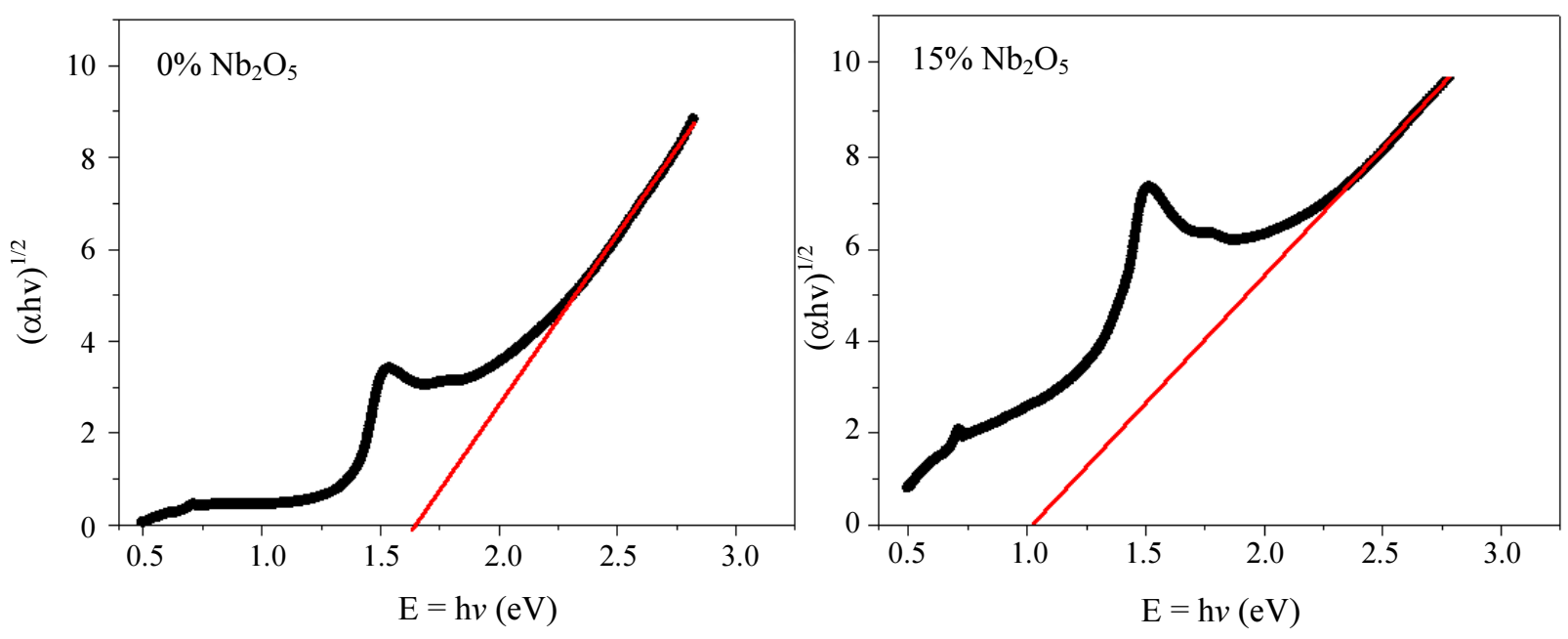

Fig. 6: $(\alpha h v)^{\frac{1}{2}}$ vs. $h v$ for indirect allowed transition in the niobium free $(\mathrm{x}=0)$ and bismuth free $(\mathrm{x}=15)$ samples

From this, one can obtain the value of the band gap for direct allowed transitions by plotting the relationship between $(a j v)^{2}$ on the ordinate axis $v s$. the photon energy $h v$ on the abscissa and by extrapolating the linear part of the curve we obtain the value from the interception on the $h v$ axis. By a similar way, the indirect allowed transitions

can be obtained by plotting the relation between $(a h v)^{\frac{1}{2}}$ and the photon energy $h v$. The values of the direct and indirect allowed transitions of sample with concentration $\mathrm{x}$ $=0$ and $\mathrm{x}=15 \mathrm{~mol} . \%$ are shown in Fig. 5 and 6 , respectively, as representative figures. The values of optical band gaps are tabulated in Table (2) for both direct allowed $\left(E_{\text {opt }}\right)^{d}$ and indirect $\left(E_{\text {opt }}\right)^{i}$ allowed transitions. By inspecting Table (2), it can be concluded that both band gaps showed slight decrease as $\mathrm{Bi}_{2} \mathrm{O}_{3}$ replaced by $\mathrm{Nb}_{2} \mathrm{O}_{5}$.

Table (2), shows the variation of both direct and indirect optical absorption energy with increasing the niobium contents in glasses. It is clear that, values of both Sand $\left(E_{\text {opt }}\right)^{i}$ are decreased until reach their lowest values at concentration $\mathrm{x}=10 \mathrm{~mol} . \%$ and then increased slightly again until reaching constant values. This result agrees with the literature (Sanghi et al., 2010). This behavior may be attributed to the contributions of two factors, the first one is the increasing of the terminal oxygen atoms number which increased by increasing the concentration of $\mathrm{Nb}_{2} \mathrm{O}_{5}$ in glass samples. This factor causes the values of both direct and indirect optical absorption energy increased by increasing $\mathrm{Nb}_{2} \mathrm{O}_{5}$ in glass samples. The second one is the decreasing fraction of $\mathrm{Bi}_{2} \mathrm{O}_{3}$ which in turn decreases the polarizability and decreases refractive index and finally decreases the values of both direct and indirect optical absorption energy gaps. It is obviously, clear that the second factor is more predominant one in these samples. Lowest values of both $\left(E_{\text {opt }}\right)^{d}$ and $\left(E_{\text {opt }}\right)^{i}$ are obtained when $\mathrm{x}=10$ mol. \%. This is the case when the concentrations of both bismuth oxide and niobium oxide are the same, i.e. it is the case, of the highest value of the number of nonbridging oxygen. This result indicates that, the sample with the best nonlinear properties is the one that has concentration $\mathrm{x}=10 \mathrm{~mol} . \%$, in which the optical band gap has its lowest value. This is because the nonlinearity of the glass system is enhanced by lowering the value of the optical band gap (Meyer et al., 1998).

\section{Conclusion}

The present work aimed at studying the effect of replacing bismuth oxide $\mathrm{Bi}_{2} \mathrm{O}_{3}$ by transition metal oxide $\mathrm{Nb}_{2} \mathrm{O}_{5}$ in the sodium bismuth borate glass, until the total replacement of $\mathrm{Bi}_{2} \mathrm{O}_{3}$ by $\mathrm{Nb}_{2} \mathrm{O}_{5}$. Structural analysis results manifested the amorphous nature of the materials and the correlation between the non-bridging oxygen and the optical absorbance of the glass system. Optical spectroscopic studies showed that the presence of niobium oxides increases the absorption coefficients of the material due to the increased amount of non-bridging oxygen in the negative ligand around the positively charged transition metal cation. It also showed that one of absorption bands is completely affected by the existence of niobium oxide due to the electronic $d-d$ transitions and the coupling between the d-electrons of $\mathrm{Nb}^{5+}$ and the vibrations of the negatively charged $\mathrm{O}^{2-}$ in the ligands. Results of optical band gap estimation manifested that the sample with lowest value of both optical band gap and subsequently the value of refractive index is the one in which $\mathrm{x}=10 \mathrm{~mol}$. \%. Which is the one in which the concentrations of both bismuth oxide and niobium oxide are the same, which has the highest number of non-bridging oxygen. This indicates that this sample is expected to have best nonlinear behavior, due to the aforementioned results. 


\section{Acknowledgement}

Authors would like to thank Prof. A.G. Mostafa, Prof. M.Y. Hassaan and Prof. M. El-Mansy for all their support and encouragement.

\section{Author's Contributions}

All authors equally contributed in this work.

\section{Ethics}

This article is original and contains unpublished material. The corresponding author confirms that all of the other authors have read and approved the manuscript and there are no ethical issues involved.

\section{References}

Almeida, J.M.P., L. De Boni, A.C. Hernandes and C.R. Mendonça, 2011. Third-order nonlinear spectra and optical limiting of lead oxifluoroborate glasses. Optics Express, 19: 17220.

DOI: 10.1364/OE.19.017220

Balachander, L., G. Ramadevudu, M. Shareefuddin, R. Sayanna and Y.C. Venudharc, 2013. IR analysis of borate glasses containing three alkali oxides. ScienceAsia, 39: 278-283.

DOI: 10.2306/SCIENCEASIA1513-1874.2013.39.278

Boyd, R.W., 2003. Nonlinear optics. Elsevier.

Cardinal, T., E. Fargin, G. Le Flem and S. Leboiteux, 1997. Correlations between structural properties of $\mathrm{Nb}_{2} \mathrm{O}_{5}-\mathrm{NaPO}_{3}-\mathrm{Na}_{2} \mathrm{~B}_{4} \mathrm{O}_{7}$ glasses and non-linear optical activities. J. Non-Crystalline Solids, 222: 228-234. DOI: 10.1016/S0022-3093(97)90118-6

Chen, Y., Q. Nie, T. Xu, S. Dai, X. Wang and X. Shen, 2008. A study of nonlinear optical properties in $\mathrm{Bi}_{2} \mathrm{O}_{3}-\mathrm{WO}_{3}-\mathrm{TeO}_{2}$ glasses. Journal of NonCrystalline Solids, 3543468-3472.

DOI: 10.1016/J.JNONCRYSOL.2008.03.005

Couzi, M., T. Cardinal, G. Le Flem and F. Evelyne, 1996. Non linear optical properties of some niobium (V) oxide glasses. Eur. J. Solid State Inorg. Chem., 33: 597-605.

Davis, E.A. and N.F. Mott, 1970. Conduction in noncrystalline systems V. Conductivity, optical absorption and photoconductivity in amorphous semiconductors. Philosophical Magazine, 22: 0903-0922. DOI: 10.1080/14786437008221061

Duffy, J.A. and M.D. Ingram, 1971. Establishment of an optical scale for Lewis basicity in inorganic oxyacids, molten salts and glasses. J. Am. Chemi. Soci., 93: 6448-6454. DOI: 10.1021/JA00753A019

Ehrt, D., 2000. Structure, properties and applications of borate glasses. Glass Technol., 41: 182-185.
El-Maaref, A.A., K.H.S. Shaaban, M. Abdelawwad and Y.B. Saddeek, 2017. Optical characterizations and Judd-Ofelt analysis of $\mathrm{Dy}^{3+}$ doped borosilicate glasses. Optical Materials, 72: 169-176. DOI: 10.1016/J.OPTMAT.2017.05.062

Farouk, M., A. Samir, F. Metawe and M. Elokr, 2013. Optical absorption and structural studies of bismuth borate glasses containing $\mathrm{Er}^{3}{ }^{+}$ions. J. NonCrystalline Solids,

DOI: 10.1016/J.JNONCRYSOL.2013.04.001

Figgis, B.N., 1987. Ligand field theory. Comprehensive Coordination Chemistry, 1:213-279.

Fragoso, W.D., C. De Mello Donegá and R.L. Longo, 2005. A structural model of $\mathrm{La}_{2} \mathrm{O}_{3}-\mathrm{Nb}_{2} \mathrm{O}_{5}-\mathrm{B}_{2} \mathrm{O}_{3}$ glasses based upon infrared and luminescence spectroscopy and quantum chemical calculations. J. Non-Crystalline Solids, 351: 3121-3126. DOI: $10.1016 /$ J.JNONCRYSOL.2005.07.031

Hodgson, J.N., 2012. Optical absorption and dispersion in solids. Springer US. books.google.com.eg/books?id=zFzSBwAAQBAJ

Junjiang, R., H. Wen, L. Jian, S. Zhenrong and H. Yuhua, 2002. Third order nonlinear optical properties of $\mathrm{TeO}_{2} \quad-\mathrm{NbO}_{2.5} \rrbracket \mathrm{PbO}$ Glass. J. Optoelectronics Laser, 13: 590-592.

Meyer, J.R., F.J. Bartoli, E.R. Youngdale and C.A. Hoffman, 1998. Effects of energy gap and band structure on freecarrier nonlinear susceptibilities in semiconductors. J. Applied Phys., 4317: 4317-4321. DOI: $10.1063 / 1.349110$

Novatski, A., A. Steimacher, A.N. Medina, A.C. Bento and M. L. Baesso et al., 2008. Relations among nonbridging oxygen, optical properties, optical basicity, and color center formation in $\mathrm{CaO}-\mathrm{MgO}$ aluminosilicate glasses. J. Applied Physics, 104: 094910. DOI: $10.1063 / 1.3010306$

Oo, H.M., H. Mohamed-Kamari and M.D. Wan-Yusoff, 2012. Optical properties of bismuth tellurite based glass. Int. J. Molecular Sci., 13: 4623-4631. DOI: 10.3390/IJMS13044623

Pal Singh, G., P. Kaur, S. Kaur and D.P. Singh, 2012. Investigation of structural, physical and optical properties of $\mathrm{CeO}_{2}-\mathrm{Bi}_{2} \mathrm{O}_{3}-\mathrm{B}_{2} \mathrm{O}_{3}$ glasses. Physica $\mathrm{B}$ : Condensed Matter, 407: 4168-4172.

DOI: $10.1016 /$ J.PHYSB.2012.06.043

Pye, D., 2005. Properties of Glass-Forming Melts. $1^{\text {st }}$ Edition. CRC Press. DOI: 10.1201/9781420027310

Rajendran, V., N. Palanivelu, B.K. Chaudhuri and K. Goswami, 2003. Characterisation of semiconducting $\mathrm{V}_{2} \mathrm{O}_{5}-\mathrm{Bi}_{2} \mathrm{O}_{3}-\mathrm{TeO}_{2}$ glasses through ultrasonic measurements. J. Non-Crystalline Solids, 320: 195-209. DOI: 10.1016/S0022-3093(03)00018-8

Rao, K.J., 2002. Structural Chemistry of Glasses. 1st Ed. Elsevier. DOI: 10.1016/B978-0-08-043958-7.X5017-1 
Rao, P.V., G.N. Raju, P.S. Prasad, C. Laxmikanth and N. Veeraiah, 2016. Transport and spectroscopic properties of nickel ions in $\mathrm{ZnOB}_{2} \mathrm{O}_{3} \mathrm{P}_{2} \mathrm{O}_{5}$ glass system. Optik-Int. J. Light Electron Optics, 127: 2920-2923.

Sanghi, S., S. Rani, A. Agarwal and V. Bhatnagar, 2010. Influence of $\mathrm{Nb}_{2} \mathrm{O}_{5}$ on the structure, optical and electrical properties of alkaline borate glasses. Materi. Chemi. Phys., 120: 381-386.

DOI: 10.1016/J.MATCHEMPHYS.2009.11.016

Sene, F.F., J.R. Martinelli and L. Gomes, 2004. Optical and structural characterization of rare earth doped niobium phosphate glasses. J. Non-Crystalline Solids, 348: 63-71.

DOI: 10.1016/J.JNONCRYSOL.2004.08.127

Sene, F.F., J.R. Martinelli and L. Gomes. 2004. Synthesis and characterization of niobium phosphate glasses containing barium and potassium. J. NonCrystalline Solids, 348: 30-37.

DOI: 10.1016/J.JNONCRYSOL.2004.08.122

Shanmugavelu, B., V.V. Ravi Kanth Kumar, R. Kuladeep and D. Narayana Rao, 2013. Third order nonlinear optical properties of bismuth zinc borate glasses. J. Applied Phys., 114: 243-103.

DOI: $10.1063 / 1.4858422$
Shelby, J.E. and M. Lopes, 2007. Introduction to glass science and technology. Cambridge: Royal Society Chemi. DOI: 10.1039/9781847551160

Stehle, C., C. Vira, D. Hogan, S. Feller and M. Affatigato, 1998. Optical and physical properties of bismuth borate glasses related to structure. Phys. Chem. Glasses, 39: 83-86.

Suhara, T., T. Hayakawa, M. Nogami and P. Thomas, 2012. Third-order nonlinear optical properties and low-frequency Raman scattering of $\mathrm{MO}-\mathrm{Nb}_{2} \mathrm{O}_{5^{-}}$ $\mathrm{TeO}_{2}$ glasses. J. University Chemi. Technol. Metallurgy, 47: 369-373.

Sutherland, R.L., 2003. Handbook of nonlinear optics. CRC Press.

Swapna, U.G. and M. Prasad, 2017. Raman, FTIR, thermal and optical properties of $\mathrm{TeO}_{2} \square \mathrm{Nb}_{2} \mathrm{O}_{5}$ प $\mathrm{B}_{2} \mathrm{O}_{3} \square \mathrm{V}_{2} \mathrm{O}_{5}$ quaternary glass system. J. Taibah University Sci., 11: 583-592.

DOI: 10.1016/J.JTUSCI.2016.02.008

Tauc, J. and A. Menth, 1972. States in the gap. J. NonCrystalline Solids, 8: 569-585.

DOI: 10.1016/0022-3093(72)90194-9

Yiannopoulos, Y.D., G.D. Chryssikos and E.I. Kamitsos, 2001. Structure and properties of alkaline earth borate glasses. Phys. Chemi. Glasses, 42: 164-172. 